\title{
DEVER FUNDAMENTAL DE ATUAÇÃO DO ESTADO COMO ELEMENTO PROMOTOR DA IGUALDADE SUBSTANCIAL E EFETIVIDADE DO SISTEMA CONSTITUCIONAL: \\ DESDOBRAMENTOS DA DIGNIDADE DA PESSOA HUMANA*
}

Marília Ferreira Silva ${ }^{\dagger}$

\begin{abstract}
RESUMO: Assiste-se à enxurrada de legislações regulando toda espécie de direitos, conferindo aos cidadãos a sensação de segurança, em vista de que são titulares das mais diversas prerrogativas jurídicas, essencialmente dos denominados direitos fundamentais, e, por este motivo, estão protegidos das mais diversas intervenções em sua esfera privada, bem como, no âmbito social. O cenário inflacionado de direitos, protagonizado pelo Estadoprovedor, tantas vezes fugindo de sua função de corrigir as desigualdades sociais, alheia os indivíduos de um relevantíssimo fator: o feedback, que no caso em apreço, corresponde à necessária obrigação de seu cumprimento (cumprimento dos direitos constitucionais), por parte dos órgãos estatais competentes. Trata-se da teoria do dever fundamental que concebe a cada direito uma prestação, seja ela de atuação ou de abstenção. Esquece-se, ou se encobre, que a excessiva oferta desses direitos nada representa se não se lhe acompanhar a concretização respectiva. Aqui, quer-se debruçar sobre aqueles direitos que exigem uma prestação estatal, que impõem a atuação positiva do Estado para que se materializem e passem a compor efetivamente, além de eficazmente, o mundo fático e jurídico dos destinatários. Mas porque a doutrina acerca desta problemática é tão escassa? Porque apenas se propugna direitos, relegando a segundo plano os correlatos deveres, especialmente o dever fundamental de atuação do Estado, do qual depende diretamente a efetividade do sistema constitucional? Não será ele (o Estado) sujeito à obrigações? Sim. Todavia, é mais interesse conceder direitos às massas, iludindo-as com a falsa aparência de sistema democrático de direito, provido de direitos, liberdades e garantias, que, de outra banda, apresentar-lhes o falho, cruel e massacrante processo de (des)cumprimento dos seus deveres, o que inviabiliza a consecução dos direitos outorgados, legitimadores do sistema constitucional, informado pelo primado da dignidade da pessoa humana.
\end{abstract}

PALAVRAS-CHAVE: Dever Fundamental; Direito Fundamental; Dignidade da Pessoa Humana; Estado Constitucional.

FUNDAMENTAL DUTY OF ACTION STATE OF PROMOTING SUBSTANTIAL EQUALITY AS AN EFFECTIVE CONSTITUTIONAL SYSTEM:

\footnotetext{
* Artigo recebido em 08/07/2013 e a provado em 06/11/2013.

*Advoga da. Assessora Jurídica do Município de Nova Cruz. Mestranda em Direito Constituci onal pela UFRN
} 


\title{
DEPLOYMENT DIGNITY OF THE HUMAN PERSON
}

\begin{abstract}
We witness the flurry of laws regulating all sorts of rights, giving citizens a sense of security, and a variety of legal prerogatives, essentially the so-called fundamental rights, and, therefore, are protected from various interventions in their private sphere as well as in the social sphere. This set full of rights, played by the state-provider, often running away from its function of correcting social inequalities, what blocks something very important to the individuals : the feedback, which in this case corresponds to the necessary requirement of compliance (compliance constitutional rights), by the State and its competences. It is the fundamental duty of the theory that conceives every right a benefit, whether acting or abstaining. By the way, the oversupply of these rights is nothing if you do not monitor the implementation thereof. Here, we want to dwell on those rights which require a state service, which impose the positive role of the state to materialize and start to write effectively, and efficiently, the factual and legal world of the recipients. But why the doctrine on this issue is so scarce? Why only the rights are known, but the correlates duties stay in the background, especially the fundamental duty of state action, which depends directly on the effectiveness of the constitutional system? Is not it (the state) subject of obligations? Yes, however, is more interested grant rights to the masses, deluding them with false appearance of democratic system of law, provided with rights, freedoms and guarantees, that otherwise, submit them flawed, cruel and grueling process of (non) compliance of their duties, what does not allow the realization of rights, that legitimize the constitutional system, based on the principle of human dignity.
\end{abstract}

KEYWORDS: Fundamental Duty; Fundamental Right; Dignity of the Human Person; Constitutional State.

\section{INTRODUÇÃO}

O presente arrazoado pretende, com brevidade, tratar da teoria que disciplina os deveres fundamentais, ${ }^{\ddagger}$ pontuando, com especialidade, de um lado, a vala de esquecimento a que são, discretamente, relegados, e, de outro, a intersecção destes para com a unidade e a efetividade do sistema constitucional hodierno.

Vivencia-se o tempo em que os direitos se multiplicam em contagem infindável, dada a velocidade com que as relações sociais surgem, modificam-se e se extinguem, cada vez maior, dentro de um Estado que tenta, a todo custo, acompanhar tal processo de evolução.

\footnotetext{
\# No vertente artigo, para fins didáticos, as expressões "deveres fundamentais" e "deveres constitucionais", devem ser entendidas sempre pela maior abrangência que possam, semântica e juridicamente, representar. Considera-se, assim, em qualquer das asserções os deveres fundamentais, os legais ou os supralegais, além dos implícitos, extraídos do sistema.
} 
A enxurrada de legislações permeia na sociedade e na consciência dos cidadãos os direitos que possuem frente ao Estado-provedor ${ }^{\S}$, as suas liberdades e garantias. E apoiada pela superação do Estado minimalista, incute nos indivíduos a plausível luta e incessante busca pela realização dos direitos inerentes à sua condição humana, tantos já preconizados pelo texto constitucional, na tentativa (in)suscetível de se formalizar completamente o universo dos direitos, o que se convém chamar de direitos fundamentais, bloco de prerrogativas que confere legitimação à própria Constituição, também conhecida como Constituição Cidadã.

Os direitos fundamentais, fins constitucionais, são, como se sabe, aqueles que exigem do Estado uma prestação e compõem o núcleo essencial do sistema constitucional, do qual se extrai a ideia de dignidade da pessoa humana. Tal atuação por parte do ente estatal, por sua vez, encontra-se vinculada à atuação político-legislativa, ao que se pode fazer referência imediata a um mecanismo de conformação do público espectador.

Mas, e os deveres fundamentais? Quem os busca tão ferozmente?

O que se tem, na verdade, é o esquecimento desta parcela do Direito que tão importante é, sem, contudo, resvalar na perca de relevância. É inimaginável realizar efetivamente um Estado Democrático de Direito pautado na igualdade substancial que incansavelmente se deseja, quando apenas se propugna a noção de direitos fundamentais, relegando a plano secundário o feedback destes, a saber, a observância dos correlatos deveres fundamentais, sejam dos próprios indivíduos ou do Estado.

É a partir desta problemática, pois, que o estudo que aqui se propõe será desenvolvido, com vistas a identificar a interligação entre as teorias dos direitos e deveres fundamentais e o sistema constitucional hodierno, ocupando-se, especialmente, do dever de atuação do Estado, apontando, por fim, possíveis formas de otimização e dissolução do dilema que se impõe em decorrência da referida imbricação.

\footnotetext{
§ Diz-se Estado-provedor não apenas vinculando-o aos direitos sociais, mas também à criação de condições para que os direitos de liberdade sejam efetivos. Considera-se, assim, ultrapassada a velha dicotomia que separa os direitos de defesa dos direitos prestacionais, pois que ambos necessitam da atuação estatal, um positiva, outro negativamente. Isto porque, transcrevendo o ensinamento de Isabel Moreira, "a liberdade dos cidadãos não é mais uma liberdade em face do (inimigo) Estado, mas configurada em termos que a sua existência depende de condições que, se não estão ao alcance do indivíduo (isto é: se este não consegue reuni-las no âmbito da sua autonomia existencial), devem ser criadas pelo Estado que as assume como tarefa". (MOREIRA, Isabel. A solução dos direitos. Coimbra: Almedina, 2007, p. 37).
} 


\section{A INTERSECÇÃO ENTRE DIGNIDADE DA PESSOA HUMANA E DEVERES FUNDAMENTAIS}

A Dignidade da Pessoa Humana representa um valor moral ${ }^{* *}$, bastando, a priori, compreender a sua vertente de primado constitucional e, como tal, definidor de consequências jurídicas.

Tal primado passou a compor o ordenamento pátrio com o advento da Constituição de 1988, período em que se processava a redemocratização das instituições domésticas, contexto no qual também se estreitavam as relações entre o direito nacional e o direito internacional, marcado pela Declaração de 1948, em resposta aos atentados contra a humanidade, protagonizados pelos nazistas.

Relativizando-se o conceito até então vigente de soberania em prol de indivíduos vulneráveis e desprotegidos, a dignidade da pessoa humana, desvinculada de qualitativos de ordem moral, cultural ou religiosos, passou a ocupar lugar central no sistema jurídico contemporâneo, impondo a sua observância nas mais diversas dimensões dogmático-jurídicas.

Bittar afirma que ao erigir valores-guia ao centro do sistema jurídico, entre eles, o da dignidade, a Constituição Federal de 1988 assumiu grande potencial transformador da sociedade brasileira, colaborando, assim, à formação fundamental da cultura dos direitos humanos dentro de uma sociedade pluralista (BITTAR, 2010, p. 250), no plano interno.

Isto porque, ainda segundo ele, a dignidade da pessoa humana é expressão que possui amplo alcance, reunindo em seu bojo todas as facetas dos direitos humanos, a exemplo da prestação de serviços essenciais por parte do Estado; do cumprimento de políticas públicas; do atendimento das necessidades sociais; da construção da justiça social; do alicerce das tomadas de decisão em política legislativa, entre outras (BITTAR, 2010, p. 255).

$\mathrm{O}$ fato é que este potencial transformador vem sendo dificultado pelo que se convencionou chamar de programaticidade das normas, adormecendo a perspectiva inovadora trazida pela Constituinte e renegando as conquistas alcançadas por esta, conferindo-lhe, ao contrário de efetividade, inocuidade.

\footnotetext{
** Ana Paula de Barcelos, neste sentido, enfatiza que, "do ponto de vista jusfilosófico, e para uma sociedade como a contemporânea, que crê nos postulados humanistas e na democracia, a dignidade da pessoa humana (aí incluindo o seu aspecto material), constitui o valor mais fundamental". (BARCELOS, Ana Paula de. A Eficácia Jurídica dos Princípios Constitucionais: O Princípio da Dignidade da Pessoa Humana. Rio de Janeiro: Renovar, 2002, p. 248).
} 
Assim é que o presente arrazoado vem avolumar os estudos que insistem em vincular o texto constitucional à dignidade da pessoa humana e à implementação dos direitos e deveres fundamentais, por quem de direito, rejeitando, com isso, a falsa sensação de conformação por parte dos cidadãos, promovida pelos dispositivos que, abstratamente, conferem-lhes os mais diversificados direitos e garantias que, por motivos vários, não saem do papel. $\dagger$

Com efeito, ao passo que a dignidade da pessoa humana se configura um direito do homem, direito subjetivo de ter sua dignidade respeitada, impõe, igualmente, um dever, a obrigação de se portar com dignidade em face de si mesmo e dos outros que consigo vivem em sociedade. Mas não só isso. Impõe, ao mesmo tempo, o dever do Estado de promover esta dignidade, de permitir que ela seja acessível aos cidadãos, pois que em nada é relevante pronunciá-la se não forem propiciadas as condições de sua materialização. Do contrário, será sempre uma abstração, não obstante provoque imensurável sedução.

Em sendo abstração apenas, perde completamente o sentido de diretriz axiológiconormativa do sistema constitucional, em vista de que a realidade social a que se destina tal sistema não necessita de mais abstrações, ilusões, mas, sim, de concretização. Concretização esta que depende frontalmente da atuação estatal quando da consecução de suas obrigações constitucionais e políticas, isto é, de seus deveres fundamentais. $\mathrm{Na}$ prática dos tribunais, importa em relevantíssimo instrumento nos processos de interpretação e ponderação. Nas duas hipóteses, pois, o princípio-mor da dignidade da pessoa humana se liberta da vagueza que the oprime, deixando de ser meramente mecanismo retórico, figura ilustrativa, para ganhar foros de relevo jurídico.

Corroborando a ideia de vinculação entre dignidade da pessoa humana e dever fundamental, Jorge Reis Novais (2011, p. 51) afirma que quando este princípio plasmado na Constituição é formalmente acolhido no respectivo texto constitucional, o que ocorreu com a realidade jurídica brasileira, além de representar, como dito, a qualidade de um valor moral legitimador da força normativo-constitucional de um Estado de Direito material, também se transforma em um dever-ser jurídico, já que vincula a atuação dos Poderes do Estado, impondo-lhes uma atividade positiva.

\footnotetext{
i† "O teor do discurso constitucional, ao deixar ambíguo, vago, ou mesmo apagado e esquecido o conteúdo significativo da dignidade da pessoa humana, pretende conferir exatamente, pela sua própria índole, de uma cruel e proposital espécie de desconsideração ao citado valor, permitindo, assim, como isto, não cumprir o seu compromisso com tal valor que é deixado a vagar pelas malhas da rede constitucional como se fos se a expressão "Dignidade da Pessoa Humana, mera figura de retórica" (LÖWENTAL, Ana Maria Valiengo. Exame da expressão 'A Dignidade da Pessoa Humana' sob o Ângulo de uma Semiótica Jurídica. In: Revista da Universidade de Ibirapuera, vol. I, n. 3, p. 28) .
} 
No plano jurídico, âmbito que interessa ao feito, conforme salienta Ana Paula de Barcelos, ao considerar especialmente a situação brasileira inaugurada com o advento da Constituição de 1988, o princípio constitucional em apreço (dignidade da pessoa humana) tornou-se o princípio estruturante, fundante da ordem jurídica e, bem assim, a finalidade estatal mais precípua, assumindo para si todas as consequências advindas, inclusive, a atividade da Hermenêutica que se impôs(õe) ao novo status conferido ao princípio, já que, como assevera Moreira, a doutrina avança para uma teorização dos direitos fundamentais enquanto princípios e valores, movendo-se no âmbito e na direção de "uma concepção de Constituição evolutiva aberta à sociedade dos intérpretes" (MOREIRA, 2007, p. 191).

Nesta esteira, há que se ter em mente sempre que a atividade reveladora do Direito não é a de prescrever dispositivos, a exemplo da atividade legislativa, mas, outrossim, a de interpretá-los ${ }^{\S}$, pois como bem ensina Eduardo Bittar, o texto jurídico é o locus da interpretação e é sempre a partir dele, e não da intenção do legislador, que parte o intérprete jurídico na busca de alcançar o sentido da proposição jurídica (BITTAR, 2010, p. 239).

Desta feita, tem-se que o princípio da dignidade da pessoa humana e a sua realização prática deve enformar, diga-se, dar forma, a todo o sistema constitucional que se declare democrático para de uma banda garantir um mínimo*** digno de direitos aos indivíduos e, de outra, assegurar o pluralismo político, elementos estruturais de qualquer Democracia.

Todavia, o que vem a ser essa dignidade?

Maria Celina Bodin de Moraes afirma ser a dignidade o elemento que distingue os seres humanos dos outros seres vivos (MORAES, 2003, p. 112). Para ela, os homens detêm uma substância única, uma qualidade própria comum unicamente à sua natureza de seres humanos.

Em estudo como Professor Visitante da Universidade de Havard, em 2011, Luís Roberto Barroso registrou que a dignidade da pessoa humana é uma realidade no mundo ocidental, um consenso ético.

Segundo a lição de Barroso, a dignidade humana é um valor fundamental que se viu convertido em princípio jurídico de estatura constitucional, seja por sua positivação em norma

\footnotetext{
\# Sobre este as sunto, conferir as lições de Peter Härbele.

$\S \S$ Conforme ensina Isabel Moreira, "a força normativa da Constituição também repousa na obrigação da interpretação mais conforme à Lei Fundamental" (op. cit., p. 224).

*** Diante da vagueza da locução "dignidade da pessoa humana", o problema que vem se impondo na atualidade é identificar qual é esse mínimo e quais efeitos concretos possui.
} 
expressa, seja por sua aceitação como um mandamento jurídico extraído do sistema (BARROSO, 2011).

Entoando a superioridade do valor "dignidade" aos homens, também Kant, um dos mais influentes filósofos do Iluminismo, citado por Moraes (2003, p. 115), chega a afirmar que assim como "as coisas têm preço; as pessoas, dignidade". Isso para refletir o dever de a legislação, a vigorar na sociedade, levar em consideração a realização desse valor carregado pelo princípio da dignidade humana, como o seu mais relevante fim.

Neste particular, a Constituição Federal de 1988 normatizou, em seu artigo 1º, III, a dignidade da pessoa humana como um dos "fundamentos da República", delineando então a tutela desse núcleo intangível, em detrimento dos valores civilistas-individualistas.

Desta feita, pode-se dizer, em consonância com a mais moderna doutrina, seguida pela mais abalizada jurisprudência, que a dignidade da pessoa humana parece ser o vetor mais poderoso, talvez o único, dentro do atual sistema constitucional, capaz de conceber a este uma sistematização axiologicamente fundamentada, necessária à iminente superação do modelo de Estado em vigor.

Segundo Junqueira de Azevedo (2002, p. 22), a consideração pelos pressupostos materiais mínimos para o exercício da vida é preceito originado no imperativo categórico da intangibilidade da vida humana, pressuposto do princípio jurídico da dignidade da pessoa humana.

Então, pergunta-se: quais são esses pressupostos mínimos? Poderia-se dizer que são os próprios direitos fundamentais plasmados na Constituição expressamente. Sim, porque se alçados à categoria de direitos fundamentais pelo documento normativo supremo, são, de fato, os componentes essenciais à existência de uma vida digna, pautada pela igualdade real. Contudo, a obviedade da resposta esbarra na generalidade dos preceitos ${ }^{\dagger \dagger i}$, especialmente daqueles que exigem uma prestação estatal, e nas dificuldades financeiras do Estado, fundamento primeiro da teoria da reserva possível $+\$$.\$§

\footnotetext{
†i† Para Dimitri Dimoulis, trata-se do fenômeno da baixa densidade normativa, que torna difícil decidir qual das partes envolvidas em um conflito está com a razão constitucional, já que interpretações conflitantes entre elas são autorizadas por um texto constitucional extremamente genérico. (DIMOULIS, Dimitri. Arguição de descumprimento de preceito fundamental. Problemas de concretização e limitação. Revista dos Tribunais, v. 832, São Paulo: Revista dos Tribunais, 2005, p. 13-16).

栝 Por ser temática objeto de grandes controvérsias, impõe estudo autônomo, detalhado, pelo que se deixa de adentrá-la.

$\$ \S \S$ O ideal é que esses conteúdos básicos da dignidade sejam universalizáveis, multiculturais, de modo a poderem ser compartilhados e desejados por toda a família humana.
} 
É, pois, a dignidade da pessoa humana que informa esse mínimo existencial, conteúdo nuclear que viabiliza uma vida digna em consonância com os preceitos constitucionais da contemporaneidade, alcançando o status de princípio jurídico ${ }^{* * * *}$, expressão de um dever-ser normativo e, por consequência, sindicável perante os Poderes estatais, pelo que resvala nos princípios da liberdade e igualdade fática.

Tal entendimento que vem se disseminando por todo o mundo ocidental, compondo as mais diversas Constituições e Tratados Internacionais, representa a passagem de um Estado de Direito para um Estado Constitucional ${ }^{\dagger i \dagger \dagger}$ que tem por meta alcançar e fornecer, por meio de estruturas jurídico-político-sociais, a plena satisfação de necessidades físicas, morais, psíquicas e espirituais do ser humano, isto é, de um "minimum exigível socialmente, capaz, por seus recursos, meios e técnicas, de alcançar justiça social” (BITTAR, 2010, p. 254), igualdade material, de onde se infere a necessidade de observar incondicionalmente o cumprimento dos deveres fundamentais por parte do Estado, responsável pelo bem-estar social, agora pautado pelo discurso jurídico da dignidade da pessoa humana, elemento de construção e aprimoramento de uma sociedade aberta e plural, o que impõe a preponderância dos demais valores sociais e que estes, juntamente com a dignidade, estejam em permanente processo de troca intersubjetiva.

Só assim, considerando a não soberania da superioridade da interpretação autêntica proposta por Kelsen, mas, sim, permitindo o agir comunicativo de Habermas (através do permanente processo de troca intersubjetiva entre os valores abrigados pela realidade constitucional e, entre eles, a dignidade da pessoa humana) poder-se-á superar a ideia ainda existente de Constituição apenas como mero documento formal, evidenciando-a como documento real, ocasião em que poderá se considerar a superação do Estado de Direito em direção a um Estado Constitucional, onde o princípio jurídico-mor da dignidade humana seja embasamento à materialização dos direitos fundamentais, fim da Constituição, a partir do cumprimento dos deveres fundamentais estatais, seja atuando positivamente ou se abstendo de

\footnotetext{
**** Segundo BARROSO, op. cit., p. 12: "Princípios são normas jurídicas com certa carga axiológica, que consagram valores ou indicam fins a serem realizados, sem explicitar comportamentos específicos. Sua aplicação poderá se dar por subsunção, mediante extração de uma regra concreta de seu enunciado abstrato, mas também mediante ponderação, em caso de colisão com outras normas de igual hierarquia. Além disso, seu papel no sistema jurídico difere do das regras, na medida em que eles se irradiam por outras normas, cond icionando seu sentido e alcance".

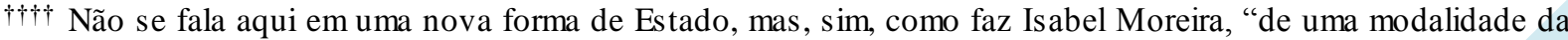
forma de Estado Democrático de Direito". Não pretendendo, portanto, substituir as tarefas antigas, mas complementá-las com novas, na busca por uma maior igualdade social. (MOREIRA, Isabel. A solução dos Direitos. Coimbra: Almedina, 2007, p. 34).
} 
tal, mas vindo, em qualquer caso, em prol das necessidades dos excluídos, marginalizados, a fim de lhes criar as condições ou thes promovendo, ao menos, mínimas oportunidades para que estes sejam (re)inseridos na sociedade. $+\ldots+$

\section{DEVER DE ATUAÇÃO DO ESTADO COMO DESDOBRAMENTO DA DIGNIDADE PESSOA HUMANA}

O catálogo de direitos fundamentais é demasiadamente extenso, conferindo aos seus titulare $\mathrm{s}^{\S \S \S}$ um extenso rol de direitos, individuais e coletivos, e suas garantias.

Ao lado desse aparato de proteção à condição do indivíduo, enquanto homem e cidadão, há, igualmente, a previsão de deveres jurídicos, de ordem individual e coletiva, tendo em vista que os direitos antes referidos não se apresentam como meros "apelos ao legislador", "programas" ou "linhas de actuação política" (QUEIROZ, 2006, p. 65).

Neste particular, os direitos sociais, cuja concretização está afeita aos órgãos estatais, exige uma atividade positiva do Estado, um dever, importando relevantes consequências jurídicas, entre eles o dever de "reposição da igualdade" (MOREIRA, 2007, p. 236) e a proibição do retrocesso social ${ }^{* * * * *}$.

Como se viu no tópico anterior, a dignidade da pessoa humana é princípio jurídico que irradia efeitos sobre todo o ordenamento jurídico, impondo, assim, que todo ele, em sua interpretação e aplicação, esteja pautado por um fundamento que confira aos seus destinatários um mínimo de dignidade.

Ao tentar fixar limites a este mínimo, buscando compreender o que é e qual o seu conteúdo, esbarra-se em dificuldades de ordem constitucional e institucional, dada a abertura da expressão da cláusula de tutela, de onde emana a imposição de que seja a dignidade da pessoa humana elemento de ponderação, além dos argumentos tangentes às dificuldades orçamentárias e estruturais do Estado.

\footnotetext{
H Hł Sobre este aspecto, diante da imposição e do crescimento de incumbências ao Estado, Isabel Moreira consigna que o atual Estado deu lugar a um novo modelo que pode ser batizado de Estado "Pós -Social" (op. cit., p. 41).

$\S \S \S$ Para o professor LEONARDO MARTINS, o estudo detalhado da questão de quem são os titulares de determinado direito é de crucial importância para a aplicação dos direitos fundamentais. Porém, como o cerne do presente estudo não é os direitos fundamentais, ousa-se não se imiscuir nesta particularidade. (MARTINS, Leonardo. Teoria Geral dos Direitos Fundamentais. São Paulo: Atlas, 2012, p. 68-69).

***** Por esta teorização, uma vez consagradas legalmente as prestações sociais, o legislador não poderá depois eliminá-las sem alternativas ou compensações, o que impõe, segundo Queiroz, "a acção do Estado, num 'dever de legislar"” (op. cit., p. 70). É tese da irreversibilidade dos direitos fundamentais.
} 
Todavia, não restam dúvidas de que cabe ao Estado-provedor implementar a consecução dos direitos fundamentais expressamente arrolados na Constituição Federal de 1988, e, bem assim, aqueles implícitos que se extraem do corpo do texto constitucional, já que dotados de eficácia plena e imediata. Esta é a questão chave diante do atual paradigma de Estado.

Isabel Moreira, em suas lições, bem ensina que ao Estado cabe garantir a todos o direito à educação, promovendo a cultura, a ciência, a educação física, o desporto, entre outros (...), bem como assegurar o direito à saúde, à segurança social, à habitação, ao trabalho, e ainda a proteção da infância, o desemprego, os idosos, etc, etc (MOREIRA, 2007, p. 36). Desta forma, estará o Estado cumprindo o seu dever de atuação, a sua função social, ao criar igualdade de oportunidades de fato, garantindo a todos a liberdade fundamental.

Não se pode descurar, a bem da verdade, que a respectiva implementação é objeto de políticas de conformação legislativa, de modo que têm a sua materialização comprometida ante a não atuação do Poder Legislativo. Ressalve-se, por oportuno, ainda, a significativa atuação do Poder Judiciário nos casos de omissão ou insuficiente realização.

O modelo de ordenamento que vem avançando reclama um balanceamento de valores, impondo o "alargamento da justiça política e o reconhecimento de um princípio de interpretação activista por parte do juiz" (MOREIRA, 2007, p. 209), e o entendimento de que os preceitos constitucionais são mandamentos que obrigam o legislador a prosseguir em sua tarefa com equilíbrio, proporção e justiça, sob pena de serem "fórmula vácua de conteúdo" (MOREIRA, 2007, p. 211), daí a relevância da atuação dos Poderes Judiciário e Legislativo.

De modo geral, por ser a realização desses direitos essenciais uma imposição do princípio da dignidade humana, pois que conferem um mínimo de dignidade à vida dos que avidamente dele necessitam, representam obrigação jurídica a cargo do Estado, impondo limite e parâmetro à sua atuação, não obstante as suas dificuldades de ordem institucional (financeira e estrutural), uma vez que é função do Estado promover a igualdade substancial, mediante a satisfação generalizada das necessidades básicas, permitindo aos cidadãos um mínimo vital. ${ }^{\dagger+1 \text { t' }}$

${ }_{\dagger}^{\dagger} \dagger \dagger \dagger$ Este dilema acerca dos argumentos fazendários e constitucionais diante da dicotomia reserva do possível $x$ mínimo existencial merece análise mais acurada em estudo autônomo, o qual não se propõe no presente artigo. 
Contudo, a doutrina jurídica muito pouco se debruça acerca dessa questão de crucial relevância, qual seja, a dimensão positiva do dever de atuação do Estado, que aponta o tipo e o nível de relação existente entre o ente estatal e os indivíduos/sociedade.

Por outro lado, todos são sabedores da "inflação de direitos" a que, cotidianamente, a sociedade é submetida. São direitos de toda a espécie. Direitos estes que, assustadoramente, padecem de efetivação, principalmente, no que atine aos direitos sociais. Esta problemática é, por sua vez, tratada rotineiramente pelos operadores e estudiosos do Direito, resvalando sempre no fosso que é a discrepância entre a realidade e o texto constitucionais. Inúmeros estudos advindos dos mais célebres constitucionalistas versam sobre a questão da ineficácia dos direitos fundamentais, com maior enfoque aos de $2^{\mathrm{a}}$ geração (direitos econômicos, sociais e culturais).

Mas, e o dever fundamental estatal de tutela? Existe um equilibrio na consideração entre os direitos e deveres fundamentais?

Nesta esteira, o Professor Leonardo Martins enfatiza que há um fortíssimo desequilibrio doutrinário. E lança a questão que incita o presente estudo, excetuando a realidade alemã: Porque a doutrina não se interessa pelos deveres fundamentais? Ao que diretamente trata de responder: deve-se à hostilidade de muitos autores quanto ao caráter antiliberal dos deveres fundamentais, bem como à sua limitada relevância nas Constituições de inspiração liberal. (MARTINS; DIMOULIS, 2012, p. 59).

De fato, a temática "deveres fundamentais" tem sido relegada a plano secundário, enquanto todos os holofotes se ocupam em apresentar os brilhantes espetáculos protagonizados pelos mais diversos direitos fundamentais e suas teorias. É o que Gomes Canotilho (2005, p. 80) denomina de "excessiva enfatização". Afinal, é politicamente mais interessante conceder direitos que tratar da (in)suscetível concretização.

José Casalta Nabais (2004, p. 15) chega a se referir ao tema "deveres fundamentais" como um daqueles que a doutrina contemporânea mais se esqueceu de tratar. Acompanhado por Ingo Sarlet que, por sua vez, aponta o quase inexistente desenvolvimento jurisprudencial e doutrinário acerca do tema no constitucionalismo brasileiro. Daí o motivo que enseja a pesquisa e a torna relevante ao panorama jurídico-constitucional hodierno, onde se assiste corriqueiramente à avassaladora avalanche de direitos reiteradamente desrespeitados e nãoimplementados pela não atuação do Estado que se furta do cumprimento de suas obrigações, impostas pela Constituição-tarefa. 
A dignidade da pessoa humana enquanto princípio jurídico irradiador de consequências jurídicas, impõe aos indivíduos que imprimam os ditames da dignidade em seus comportamentos nas relações com os outros indivíduos, para com a sociedade como um todo e, também, para consigo mesmo.

Relativamente ao Estado, como salienta Jorge Reis Novais (2011, p. 52), a exigência moral de respeito pelos ditames de uma vida digna é, igualmente, critério de valoração da legitimidade de sua atuação e, bem assim, fundamento apto a invalidar qualquer ato que contrarie tais ditames, emanados de qualquer um dos poderes do Estado que promova a violação.

Assim, em tendo a Constituição de 1988 elevado o princípio da dignidade humana a fundamento da República, obrigou o Estado a conformar toda a sua ordem jurídica neste sentido, vinculando seus Poderes a atuarem em conformidade com os preceitos emanados deste princípio jurídico, fundamento estruturante da República brasileira.

Por assim ser, cabe ao Estado dispor de mecanismos de prevenção, proteção e promoção da dignidade da pessoa humana em face de desafortunadas intervenções que tendam a desafiá-lo, em razão de que ao projetá-la como fundamento republicano, afasta o Estado da ideia de que possui um fim em si mesmo, aproximando-o da ideia de que é a pessoa que é fim em si mesmo (NOVAIS, 2011, p. 52), de que existe para servir as pessoas e tornalas iguais. Iguais, diga-se de passagem, não apenas perante a lei, mas, sim, e principalmente, entre elas mesmas, iguais em chances.

Percebe-se que a Constituinte, no Capítulo I (Direitos e Deveres Individuais $e$ Coletivos) do Título II (Direitos e Garantias Fundamentais), ocupou-se de trazer expressamente deveres fundamentais, devendo-se somar a estes, ainda, outras passagens que se encontram esparsas no texto além daqueles deveres implicitamente extraídos.

Já fora mencionado antes que é inimaginável passar pelo estágio evolutivo de um Estado Democrático de Direito, propugnando-se apenas direitos e desconsiderando os deveres. Tanto assim o é que o legislador constituinte optou por inseri-los no mesmo capítulo, unindo-os sistematicamente. Aos indivíduos portadores de direitos, também são atribuídos deveres para com os outros, para com a sociedade e consigo mesmo.

Nesta oportunidade, interessam os deveres atinentes à atividade do Estado, enquanto Estado-provedor-interventor, em prol da realização do princípio-vetor da dignidade, através da sua obrigação de respeitar aquilo que se oferece pela Constituição, cumprindo-a, sem, 
contudo, afetar desnecessária ou desproporcionalmente a autonomia individual. Do contrário, vivenciar-se-ia um retrocesso inaceitável, essencialmente porque a liberdade, ao lado da igualdade e da solidariedade social, são desdobramentos da dignidade da pessoa humana.

Direitos e deveres fundamentais possuem uma forte relação de imbricação, de modo que a materialização dos direitos fundamentais sociais, por exemplo, depende diretamente do cumprimento do dever de atuação positiva do Estado. $++1+$ De outro modo, registre-se o dever correlato ao direito de um mesmo indivíduo, a exemplo do direito ao meio ambiente saudável correlato ao dever de preservação do meio ambiente, modalidade que não é objeto do estudo vertente, ocupado com a modalidade dever fundamental de atuação do Estado quanto ao cumprimento dos direitos fundamentais.

Desta feita, impõe para que se tenha um sistema constitucional uno e efetivo que o Estado assuma para si as responsabilidades que the são atinentes, entre elas o dever estatal de tutela, entendido no seu sentido mais amplo, não restrito aos que se encontram na Constituição, mas também os supralegais e legais.

Martins e Dimitri consignam que o dever estatal de tutela refere-se ao dever do Estado de proteger ativamente o direito fundamental contra ameaças de violação provenientes, sobretudo, de particulares.

E quem protege o direito fundamental contra a violação e/ou omissão proveniente do próprio Estado? O que legitima esse dever estatal de atuação?

Após todo o delineado, fica fácil inferir: a dignidade da pessoa humana.

Segundo a Grundgesetz, ${ }^{\S \S \S \S}$ o Estado é obrigado a observar e a proteger a dignidade da pessoa humana, concepção da dogmática do efeito horizontal que deve ser levada a efeito pelo constitucionalismo brasileiro.

A teor do que antes fora esposado, a dignidade é fundamento da República brasileira e vincula o Estado a the dar espaço, pelo que a cada direito fundamental previsto ao indivíduo, há um dever fundamental que obriga o ente estatal a atuar positiva ou negativamente, observando, protegendo e/ou cumprindo o preceito constitucional.

Deste modo, não cabe ao Estado apenas se abster de comportamentos lesivos, ou seja, de não intervir nas esferas individuais protegidas, e proteger ativamente os direitos

\footnotetext{
H+\# Há de se ressalvar que à existência de um direito nem sempre corresponde a existência de um dever, salvo se a intenção for dizer que ao direito de um implica o dever de reconhecimento e respeito do outro.

$\S \S \S \S$ Lei Fundamental alemã (art. 1, I, 2, GG). Saliente-se que a dogmática do dever estatal de tutela foi desenvolvida pela jurisprudência do Tribunal Constitucional alemão, doutrina essa ainda não completamente sistematizada.
} 
fundamentais em face de possíveis inobservâncias por particulares, como ensina Martins (2012, p. 114). Cabe-lhe mais. Cabe-lhe o dever jurídico de dar efetivo cumprimento aos preceitos constitucionais traduzidos pelos direitos fundamentais, fins constitucionais. São os deveres de prestação do Estado, pelos quais se põe em prática serviços e políticas públicas para a concretização desses direitos que legitimam todo o sistema constitucional. E tal não o é apenas para se desincumbir de um ônus, mas, sim, porque "dele depende o desenvolvimento e o progresso da pátria” (ÁVILA, 1967, p. 159).

Caso contrário, a quem cabe realizar o extenso rol de direitos fundamentais desrespeitados e não implementados, mas fartamente encontrados na Constituição? Se não se buscar conferir juridicidade ao dever de atuação do Estado, não obstante que o seja mediante a via judicial, estes tais direitos que conferem ao Estado Brasileiro o caráter Democrático, não passaram de figuras ornamentais, ilusórias, servientes aos grupos de poder, em detrimento das massas, reiteradamente enganadas, iludidas, esquecidas, mola propulsora da crise institucional vivenciada.

Isto porque a concepção moderna do Direito não preenche mais as expectativas da sociedade, impondo-se pelas novas necessidades da pós-modernidade uma concepção funcional, em que as interpretações jurídicas sejam feitas com o escopo de assegurar eficácia concretiva aos comandos normativos à luz da dignidade humana, como forma de se realizar valores intrínsecos à manutenção do Estado como a igualdade (material) e a liberdade.

Por esta razão é que pôr a dignidade da pessoa humana efetivamente no cume do sistema constitucional se impõe, pois que ela carrea toda a carga de demandas pela realização da Justiça, fim primeiro colimado pelo Direito. No que diz respeito ao dever de atuação estatal em prol da sociedade e dos indivíduos, serve a dignidade humana como elemento unificador do sistema e, bem assim, como "uma grande referência no sentido da necessidade de proteção dos valores fundamentais constitucionais conquistados pela humanidade" (BITTAR, 2010, p. 261), ocasião em que se promove e densifica a otimização do sistema constitucional, dandolhe maior efetividade e evitando que o Estado se utilize de seus direitos e deveres como instrumentos de manipulação de muitos, no interesse de poucos.

Urge cobrar o respeito ao pacto inicial, fazendo cumprir as cláusulas sociais indispensáveis à dignidade humana e à sobrevivência, em prol da proclamada igualdade substancial. 


\section{CONCLUSÃO}

As teorias dos direitos fundamentais e seus mais espetaculares compêndios praticamente anularam, num processo contínuo, diga-se de passagem, a categoria dos deveres fundamentais, provavelmente impulsionadas por uma retaliação ao período em que apenas estes figuravam no cenário sócio-jurídico.

Todavia, na ordem constitucional hodierna, impõe-se o imediato reconhecimento da simbiose permanente e necessária entre essas duas vertentes do Direito, os direitos e os deveres, sejam eles dos cidadãos, dos homens públicos ou do Estado.

No breve estudo elaborado neste, não obstante a escassa doutrina a respeito, sem descurar de sua imensidão a explorar, analisou-se uma espécie do gênero deveres fundamentais, qual seja o dever de atuação estatal, pelo qual o Estado-provedor encontra-se obrigado pelas circunstâncias sociais, políticas e jurídicas, a dar cumprimento e efetividade aos dispositivos constitucionais, essencialmente porque eles são desdobramentos do primado da dignidade da pessoa humana, princípio jurídico maior que informa toda a ordem constitucional, e disso depende a manutenção do sistema constitucional vivo e complacente com as demandas sociais.

É, pois, o que a pós-modernidade e os avanços do Direito em direção a um Estado Constitucional reclama para que se possa preencher as lacunas deixadas pelas teorias dos direitos fundamentais: que sejam sopesados os direitos em face dos deveres e vice-versa, que estas duas realidades sejam postas em relação de interdependência, e que os cidadãos conscientizem-se dos deveres e da necessidade de cobro de sua observância, do que estar a depender muitos dos problemas enfrentados pela ordem constitucional, entre eles, a afamada discrepância entre o texto e a realidade constitucionais.

Esta perspectiva se torna muito mais relevante quando o que se põe em xeque são os direitos e deveres fundamentais, onde se tem o Estado como sujeito passivo, obrigado a atuar positivamente. Isto porque o acesso efetivo àqueles dependem direta e umbilicalmente do cumprimento destes. Logo, se há deficiência no final da cadeia, ocasião da consecução dos direitos em atendimento aos deveres, dada a negligência do ente estatal, resta completamente comprometido o sistema constitucional.

Sabe-se que o sistema constitucional sobrevive de dois elementos basilares, quais sejam, a sua unidade e efetividade, sem os quais todo o sentido de sistema democrático de 
direito se esvai, em vista de que nada representa o mais extenso rol de direitos fundamentais compendiados e outorgados a destinatários identificados ou identificáveis, se não se alcança o mínimo de materialização.

Viu-se que o referido mínimo sofre por ausência de determinação concreta, já que a doutrina esbarra em obstáculos de ordem constitucional e institucional ao tentar fixar limites ao seu conteúdo.

Porém, ante a vivência da superação do Estado Democrático de Direito em prol de um Estado Constitucional, emerge a dignidade da pessoa humana como a luz no fim túnel. É a dignidade humana que, saindo de sua abstração, como alegam os retrógrados, impõe parâmetros à atuação estatal, definindo, por seus ditames, o que vem a ser um mínimo digno diante do caso concreto.

Por fim, ante o convencimento da importância de se elevar a teoria dos deveres fundamentais, especialmente dos deveres de atuação do Estado, ao patamar em que se coloca a teoria dos direitos fundamentais, conclama-se os cidadãos a assumir uma postura ativa, a exigir o cumprimento daquilo que the fora conferido como direito subjetivo, fundamental, daquele que tem a obrigação, o dever de o fazer, o Estado, controlando-os. Esta contribuição é fundamental.

Unicamente desta forma, em consonância com as constantes mutações sociais e imposições da pós-modernidade, a busca pela sonhada e desejada igualdade material, encontrará um ambiente social, político e jurídico fértil, onde germinarão direitos atrelados ao dever cumpridor do Estado, oportunidade na qual o sistema constitucional, renovado, triunfará uno e efetivo, apto a ser realizado, pautado por preceitos que não serão, o que Lassale há muito já propunha, mera folha de papel.

\section{REFERÊNCIAS}

ÁVILA, Fernando Bastos de. Pequena Enciclopédia de Moral e Civismo. Rio de Janeiro: Companhia Nacional de Material de Ensino, Ministério da Educação e Cultura - MEC, 1967.

AZEVEDO, Antônio Junqueira de. A caracterização jurídica da dignidade da pessoa humana. Revista dos Tribunais, v.91, n.797, p. 11-26, mar. 2002.

BARCElOS, Ana Paula de. A Eficácia Jurídica dos Princípios Constitucionais: O Princípio da Dignidade da Pessoa Humana. Rio de Janeiro: Renovar, 2002. 
BARROSO, Luís Roberto. A dignidade da pessoa humana no direito constitucional contemporâneo: natureza jurídica, conteúdos mínimos e critérios de aplicação. Interesse Público, Belo Horizonte, v. 14, n. 76, nov./jun. 2012. Disponível em:

<http://bdjur.stj.jus.br/dspace/handle/2011/52440>. Acesso em: 6 fev. 2013.

BITTAR, Eduardo C. B. Hermenêutica e Constituição: A dignidade da Pessoa Humana como legado à Pós-Modernidade. In: Dignidade da Pessoa Humana: Fundamentos e Critérios Interpretativos. (Org. ALMEIDA FILHO, Agassiz; MEGARÉ, Plínio). São Paulo: Malheiros, 2010.

CANOTILHO, José Joaquim Gomes. Das constituições dos direitos à crítica dos direitos. Direito Público, Brasília, n. 7, 2005.

DIMOULIS, Dimitri. Arguição de descumprimento de preceito fundamental. Problemas de concretização e limitação. Revista dos Tribunais, v. 832, São Paulo: Revista dos Tribunais, 2005.

LÖWENTAL, Ana Maria Valiengo. Exame da expressão 'A Dignidade da Pessoa Humana' sob o Ângulo de uma Semiótica Jurídica. In: Revista da Universidade de Ibirapuera, vol. I, n. 3.

MARTINS, Leonardo; DIMOULIS, Dimitri. Teoria Geral dos Direitos Fundamentais. São Paulo: Atlas, 2012.

MORAES, Maria Celina B. de. O conceito de dignidade da pessoa humana: substrato axiológico e conteúdo normativo. In: SARLET, Ingo Wolfgang (Org.). Constituição, Direitos Fundamentais e Direito Privado. Porto Alegre: Livraria do Advogado, 2003.

MOREIRA, Isabel. A solução dos direitos. Coimbra: Almedina, 2007.

NABAIS, José Casalta. O dever fundamental de pagar impostos: contributo para a compreensão constitucional do estado fiscal contemporâneo. Coimbra: Almedina, 2004.

NOVAIS, Jorge Reis. Os Princípios Constitucionais Estruturantes da República Portuguesa. Coimbra: Coimbra, 2011.

QUEIROZ, Cristina. O Princípio da Não Reversibilidade dos Direitos Fundamentais. Coimbra: Coimbra, 2006. 